\title{
XXXVIII. The disruptive voltage of thin liquid films between iridio-platinum electrodes. Part I. Voltages 25-400
}

\section{P.E. Shaw B.A. D.Sc.}

To cite this article: P.E. Shaw B.A. D.Sc. (1906) XXXVIII. The disruptive voltage of thin liquid films between iridio-platinum electrodes. Part I. Voltages 25-400, Philosophical Magazine Series 6, 12:70, 317-329, DOI: 10.1080/14786440609463546

To link to this article: http://dx.doi.org/10.1080/14786440609463546

曲 Published online: 16 Apr 2009.

Submit your article to this journal $₫$

Q View related articles ¿

4 Citing articles: 1 View citing articles 준 
Dissuptive Voltage of Thin Liquid Films.

When (18) holds this simplifies still further to the form

$$
\mathrm{C}=\frac{\mathrm{PS}-\mathrm{QR}}{f(\mathrm{~K}+\mathrm{S})} \cdot \frac{\mathrm{E}}{\mathrm{F}+\frac{\mathrm{R}^{\prime} \mathrm{S}^{\prime}}{\mathbf{R}^{\prime}+\mathrm{S}^{\prime}},}
$$

in the first factor of which pure resistances only occur. Hence

$$
\mathrm{C}=\frac{\mathrm{PS}-\mathrm{QR}}{\mathrm{Q}(\mathbf{R}+\mathrm{S})} \mathrm{C}^{\prime},
$$

which shows that the curves for the two currents are exactly of the same shape. 'The cominutator positions at which the galvanometer deflexions are reduced to zero in the two cases will be consequently identical.

XXXVIII. The Disruptive Voltage of Thin Liquid Films between Iridio-Platinum Electrodes. Part I. Voltages 25-400. By P. E. Shaw, B.A., D.Sc.* LECTRIC-TOUCH measurements can readily be made under oil. If a telephone be included in the circuit, the sounds made in contuct are sharp and clear for all the liquids mentioned below. They even excel air in this respect. This property of oils to render contact distinct has been used in potentiometers and other instrumenis. The whole instrument, or at least the slide-wire, is immersed in paraffin oil (soe a paper by R. A. Lehfeldt and discussion following, in Phys. Soc. Proc. p. 479, 1901-1903). This previous use of oils suggested the present research.

The relation of spark-length to small P.D. of the electrodes has been experimentally tested for gases by Earhart (Phil. Mag. [6] i. p. 147, 1901), Shaw (Proc. Roy. Soc. vol. Ixxiii. p. 337, 1903), Kinsley (Phil. Mag. May 1905, p. 692), and Hobbs (Phil. Mag. [6] x. Dec. 1905).

Earhart discovered the knee occurring in the curve at 350 volts. Shaw pushed the investigation further by using small P.D. down to $\frac{1}{2}$ volt. Kinsley threw doubt on the constancy of potential for a given gas and given electrodes. Hobbs, working more exhaustively than his predecessors, has added much detinite and useful information.

The discharge in gases must bear a close relationship to the discharge in liquids, but little precise work has been done on the latter, though Hughes (Proc. Inst. Elec. Eng. 1892), Swinton (Discussion on the above paper), Steinmetz ('Trans. Amer. Inst. Elec. Eng. 1893), before 1903, and recently, C. E. Skinner (Nat. Elec. Light Assoc., Boston, Mass., 1904),

* Communicated by the Physical Society : read June 22, 1906. 
318 Dr. P. E. Shaw on the Disruptive Voltage of Thin

Przibram (Akad. Wiss. Wien, Sit r-Ber. Nov. 1904), and Voege (Elektrotechn. Zeitschr. Dec. 1904) have tested the relationship for spark-lengths greater than ${ }_{20}^{\mathrm{T}} \mathrm{mm}$.

In the following paper the P.D. varies from 25 volts to 400 volts, and the corresponding spark-lengths vary from ${ }_{1}^{3} \sigma$ micron (micron $={ }_{T 00}^{1} 0 \mathrm{~mm}$.) to about 10 microns.

Recently a book on the subject has been published giving useful information ("The Insulation of Electric Machines," by $\mathrm{H}$. W. Turner and H. M. Hobart, Whitaker \& Co., Paternoster Sq., E.(C.). It is made clear in this book that water, acids, and alkalies are very destructive of the insulating powers of oils ; thus Skinner has shown that 50 per cent. of water reduces the dielectric strength of transformer oil to half its value when quite dry.

In the present work all the commercial liquids used were shaken up and allowed to remain over potassium carbonate, filtered, and then heated to $110^{\circ}$ for several hours, then liept in a glass-stoppered bottle till used.

\section{Method.}

In a research by the present writer on the sparkingdistance in air (loc. cit.), the electric micrometer with levers was used to measure spark-length ; in the present case the electric micrometer, without levers, is used. It has been already described (Proc. Roy. Soc. April 1906) for measuring gauges; it has proved very convenient for the present experiments.

The only parts of the apparatus which need be here mentioned can be understood from fig. 1. Two spindles, A and B3, are in one line, and can be worked to or from one another

Fig. 1.

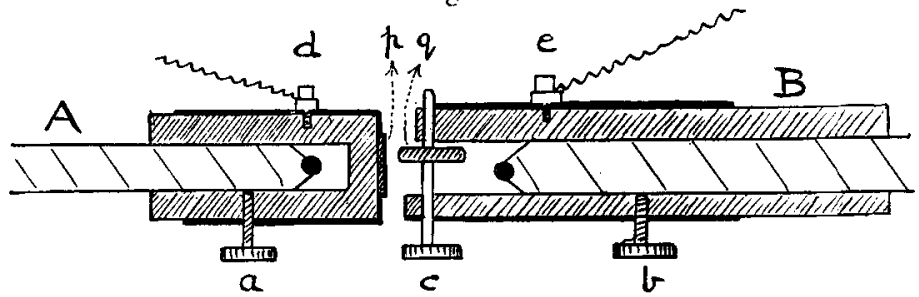

by micrometer-screws not shown, and their distance apart can be read and controlled to $\frac{1}{100} \mu$ (i.e., $\frac{1}{100,000} \mathrm{~mm}$.). The divisions on the micrometer-head show movements of $1 \mu$, and these, when viewed by a microscope, can be each subdivided into 100 parts. 
On A and B are filted two caps of ebonite clamper on by screws $a, b$. Mounted on each ebonite is a sheath of steel. On the left cap is a plate of iridio-platinum $p$, and on the right is a disk of iridio-platinum $q$, set on a spindle turning on an axis in the plane of the paper and perpendicular to $B$. This disk projects, as shown, so that when B advances to A, the surlaces $q$ and $p$ are brought into contact. Since $q$ is a diametral section of a sphere, its elge touches the plate $p$ at a point. Discharge is made to occur between $p$ and $q$. By causing $p$ to rotate on a horizontal axis along $A$ and $q$ to rotate on a horizontal axis perpendicular to $\mathrm{B}$, fresh surfaces of $p$ and $q$ can be presented to one another continually, since $q$ tonches $p$ not at the centre.

The P.D. on surfices $p, q$ is maintained by connecting wires to terminals $d e$. The full circait is shown in fig. 2 . Here a 400-volt lighting circuit is joined through key $K_{4}$ to a water resistance. Between the fixed zinc electrodes $Z_{1}, Z_{3}$ is the full P.D., while between the moveable $Z_{2}$ and the fixed $Z_{1}$ is the P.D., say V, used in discharging the apparatus. The leads to the electrodes $Z_{2}$ and $Z_{3}$ are insulated from the liquids by being enclosed in glass tnbing.

If switches $K_{2}$ and $K_{3}$ are put over to the right, the above voltage $V$ will act through the voltmeter $V_{0}$ or on the discharge surfaces $p, q$ according as the keys $K_{5}$ and $K_{6}$ are put over to the left or the right.

It is easy to vary the P.D. used by moving $Z_{2}$.

Another circuit is on the left and is brought into action by putting switches $K_{2}$ and $K_{a}$ over to the left, whilst $K_{5}$ and $\mathrm{K}_{6}$ are kept to the right. The sing'e cell $\mathrm{C}$ has resistance $r_{1}$, say $100 \mathrm{ohms}$, and $r_{2}$, say $4000 \mathrm{ohms}$, in circuit. The telephone T is in the circuit and sounds when $p$ and $q$ touch. This circuit is used to determine the position of contact of $p$ and $q$, the P.D. between them bein $r$ very small, in this case $\frac{1}{40}$ volt. The actual discharge for high potential experiments, say 100 volts, from the right circuit, takes piace when $p$ and $q$ are separated by a small gap; but the dischargedistance for the small voltage $\frac{1}{40}$ volt of the left circuit is so minute that it can be ignored. The above apparatus can be used for discharge through gases, liquids, or solids.

The modus operandi for liquids is as follows:-The caps on spindles A B are removed from the spindles, the iridioplatinum surfaces gronnd with finest emery to remove the old surface, polished with rouge or leather, and eleaned. The caps are piaced on $A$ and $B$ and $p, q$ made to approach. One drop of the liquid to be tested is placed on $q$, and as $p$ appruaches $q$ the liquid settles by capillarity between $p$ and $q$. 
Then the spindle $B$ is moved slightly away, the liquid being thus drawn out into a thread connecting the surfaces, and there is a guarantee that liquid without air-bubble connects the surfaces. The switches $K_{2}$ and $K_{3}$ are put to the left,

Fig. :..

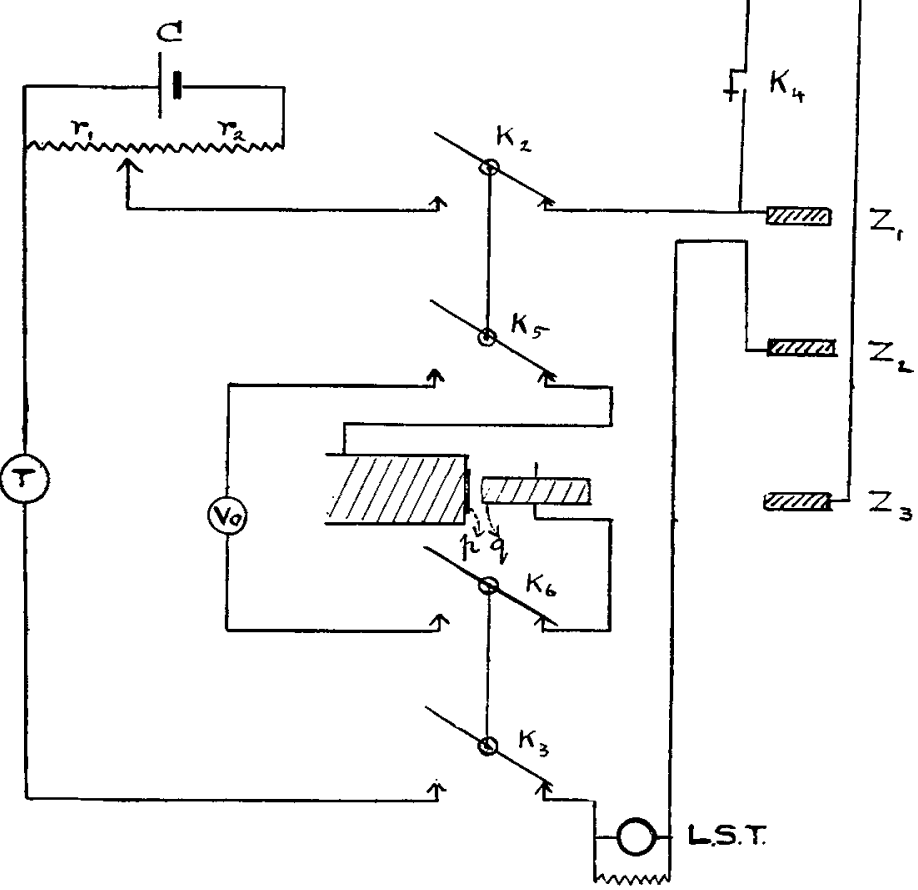

and $\mathrm{K}_{5}$ and $\mathrm{K}_{6}$ put over to the right. If now $p$ is advanced and touches $q$, the telephone $\mathrm{T}$ sounds ; the reading of the divided head of the right micrometer-wheel is taken. This is the first reading. The surface $q$ is drawn away from $p$ about twice as far as the spark-length about to occur. Switches $K_{2}$ and $K_{3}$ are put to the right, and $K_{5}$ and $K_{6}$ put to the left. The position of $Z_{2}$ is arranged so that the voltmeter shows the desired P.D. Now $K_{5}$ and $K_{6}$ are put over to the right, and $q$ is mide very slowly to approach $p$, the micrometer-scale being watched so that at the moment when discharge occurs and is indicated by the sounding of tel"phone L.S.T., the scale is read a second time. The discharge-distance is the difference between the first and second readings. 
These distances are entered in the tables following in units which are $0.01 \mu\left(\mu=\right.$ micron $\left.=\frac{1}{1000} \mathrm{~mm}\right)$.

The surfaces of $p, q$ presented to one another are renewed, as shown above, by rotations and another discharge is made.

Most of the liquids used are of commercial quality, and are purified as shown above; others were obtained specially pure. The following liquids were tested :-

Vegetable Oils.-U Ulive oil, castor oil, linseed oil, rape oil. Also turpentine, fusel oil, and oil of resin.

Animal Oils.-Cod-liver oil, neats-foot oil.

Mineral Oils.-Paraffin, transformer oil.

A Homologous Series.-Pentane $\left(\mathrm{C}_{5} \mathrm{H}_{12}\right)$; hexane $\left(\mathrm{C}_{6} \mathrm{H}_{14}\right)$; heptane $\left(\mathrm{C}_{7} \dot{\mathrm{H}}_{16}\right)$; octane $\left(\mathrm{C}_{8} \mathrm{H}_{18}\right)$. These were obtained from C. A. F. Kahlbaum, Berlin. Hexane and octane were specially pure, being derived from propyl iodide and octyl iodide respectively ; while heptane and pentane were obtained from petroleum.

Varnishes.-Of these armacell and ohmaline are obtained from Griffiths Bros., Bermondsey, London ; while Sterling varnish is made by The Sterling Varnish Co., Manchester. Though these are made to insulate when dry, they all have great dielectric strength when liquid, as shown in the curves 'fig. 5).

TABLE $\mathrm{I}$.

$l=$ spark-length stated in units of $0 \cdot 01 \mu$.

\begin{tabular}{|c|c|c|c|c|c|c|c|}
\hline \multirow{2}{*}{$\begin{array}{l}\text { P.D. } \\
\text { in rolts. }\end{array}$} & \multicolumn{7}{|c|}{$l}$. \\
\hline & $\begin{array}{l}\text { Olive } \\
\text { Oil. }\end{array}$ & $\begin{array}{c}\text { Linseed } \\
\text { Oil. }\end{array}$ & $\begin{array}{c}\text { Castor } \\
\text { Oil. }\end{array}$ & $\begin{array}{l}\text { Rape } \\
\text { Oil. }\end{array}$ & $\begin{array}{c}\text { Turpen- } \\
\text { tine. }\end{array}$ & $\begin{array}{c}\text { Fusel } \\
\text { Oil. }\end{array}$ & Air. \\
\hline $\begin{array}{l}375 \\
350\end{array}$ & $\begin{array}{l}560 \\
510\end{array}$ & $\begin{array}{l}550 \\
475\end{array}$ & $\begin{array}{l}570 \\
520\end{array}$ & 610 & 520 & $\begin{array}{l}550 \\
\ldots\end{array}$ & $\begin{array}{l}1300 \\
1100\end{array}$ \\
\hline 300 & 445 & 350 & 400 & 430 & 420 & ... & $\begin{array}{l}160.250 \\
480.320\end{array}$ \\
\hline 275 & & & & & & & 120 \\
\hline 250 & 400 & 300 & 350 & 400 & 340 & 300 & 118 \\
\hline 200 & & 220 & $\cdots$ & 300 & 220 & 255 & 100 \\
\hline 186 & 340 & & 318 & & 165 & & \\
\hline $\mathbf{1 5 0}$ & 290 & 190 & 275 & 220 & 120 & 205 & 80 \\
\hline 125 & 235 & 150 & 210 & & 100 & & 48 \\
\hline 100 & 200 & 95 & 170 & 115 & 90 & 150 & 46 \\
\hline 75 & 145 & $\ldots$ & 150 & 115 & 80 & 110 & 36 \\
\hline 70 & 140 & & & & & & \\
\hline 68 & 115 & & & & & & \\
\hline 66 & 93 & & 110 & & & & \\
\hline 50 & 60 & 56 & 58 & $4 \check{5}$ & 55 & 80 & 14 \\
\hline 25 & 27 & 27 & 35 & $\ldots$ & 27 & 35 & 8 \\
\hline 10 & 11 & & & & & & \\
\hline
\end{tabular}

Phil. Mag. S. 6. Vol. 12. No. 70. Gci. 1906. 
322 Dr. P. E. Shaw on the Disruptive Voltage of Thin

TABLE II.

\begin{tabular}{|c|c|c|c|c|c|c|c|}
\hline \multirow{2}{*}{$\begin{array}{l}\text { P.D. } \\
\text { in volts. }\end{array}$} & \multicolumn{7}{|c|}{ l. } \\
\hline & $\begin{array}{c}\text { Paraffin } \\
\text { Oil. }\end{array}$ & $\begin{array}{c}\text { Trans- } \\
\text { former Oil }\end{array}$ & $\begin{array}{l}\text { Cod-lirer } \\
\text { Oil. }\end{array}$ & Pentare. & $\begin{array}{l}\text { Hex- } \\
\text { ane. }\end{array}$ & $\begin{array}{l}\text { Hept- } \\
\text { ane. }\end{array}$ & Octane. \\
\hline 390 & & & 450 & & & & \\
\hline 345 & bleaks & breaks & 395 & 400 & 260 & 820 & 350 \\
\hline 300 & down & down. & 350 & 250 & & 260 & 310 \\
\hline 250 & readily. & & 290 & 220 & 220 & 275 & \\
\hline 200 & & 350 & $\ldots$ & 170 & $2: 0$ & 235 & 240 \\
\hline 175 & 350 & & & & & & \\
\hline 150 & 300 & 210 & 175 & 145 & 170 & 140 & 180 \\
\hline $\begin{array}{l}125 \\
100\end{array}$ & $\begin{array}{l}220 \\
180\end{array}$ & $\begin{array}{l}170 \\
110\end{array}$ & $\begin{array}{l}150 \\
120\end{array}$ & 90 & 150 & 100 & 105 \\
\hline 75 & 55 & 80 & & & & & \\
\hline $\begin{array}{l}62 \\
56\end{array}$ & $\begin{array}{r}125 \\
05\end{array}$ & & & & & & \\
\hline 50 & 75 & 70 & 50 & 50 & 80 & 50 & \\
\hline 25 & 38 & & & & & & \\
\hline
\end{tabular}

As all experimenters on gaseous discharge have found, the discharge-distance is an uncertain measurement. The same order of error occurs for liquids. In the case of gases, dust or want of polish increases the distance of discharge for a given P.D. In liquids, solid or flocculent substances or minute airbubbles may be floating, or the presence of water, acid, alkali, or salts will set up electrolysis and change the dischargedistance.

In the curves below (figs. $3,4,5$ ) some liquids may be represented rougbly by straight lines; other liquids certainly require irregular curves for proper representation. They may be classed as follows :-

Straight Curves.
Linseed Oil.
Rape ",
Fusel "
Cod-liver "
Pentane.
Octane.
Armacell Varnish.
Ohmaline ",
Sterling "

Irregular Curves.

Paraffin Oil.

Transformer ,

Castor

Olive "

Turpentine.

Hexane.

Heptane.

Though this classification is convenient, there is no sharp demarcation between the two classes above. Only those liquids are placed in the second class for which it would be absurd to suppose the departure from a straight line could be due to experimental errors. 
Liquid Films between Iridio-platinum Electrodes. 323

In the cases of castor oil, olive oil, and paraffin there appears to be a distinct an $l$ similar variation in potential gradient for discharge-distances between $1 \mu$ and $2 \mu$ (see fig. 4).

The air curve is given for reference.

Hobbs (loc. cit.) has shown that potential gradient near the origin depends on the metal of which the electrodes are made, every metal having a different gralient from every other.

The electrodes used throughout these researches are iridioplatinum. The gradient for this alloy is steeper (220 volts per micron) than any found by Hobbs, though he found platinum to have a high gradient ( 160 volts per micron).

Fig. 3.

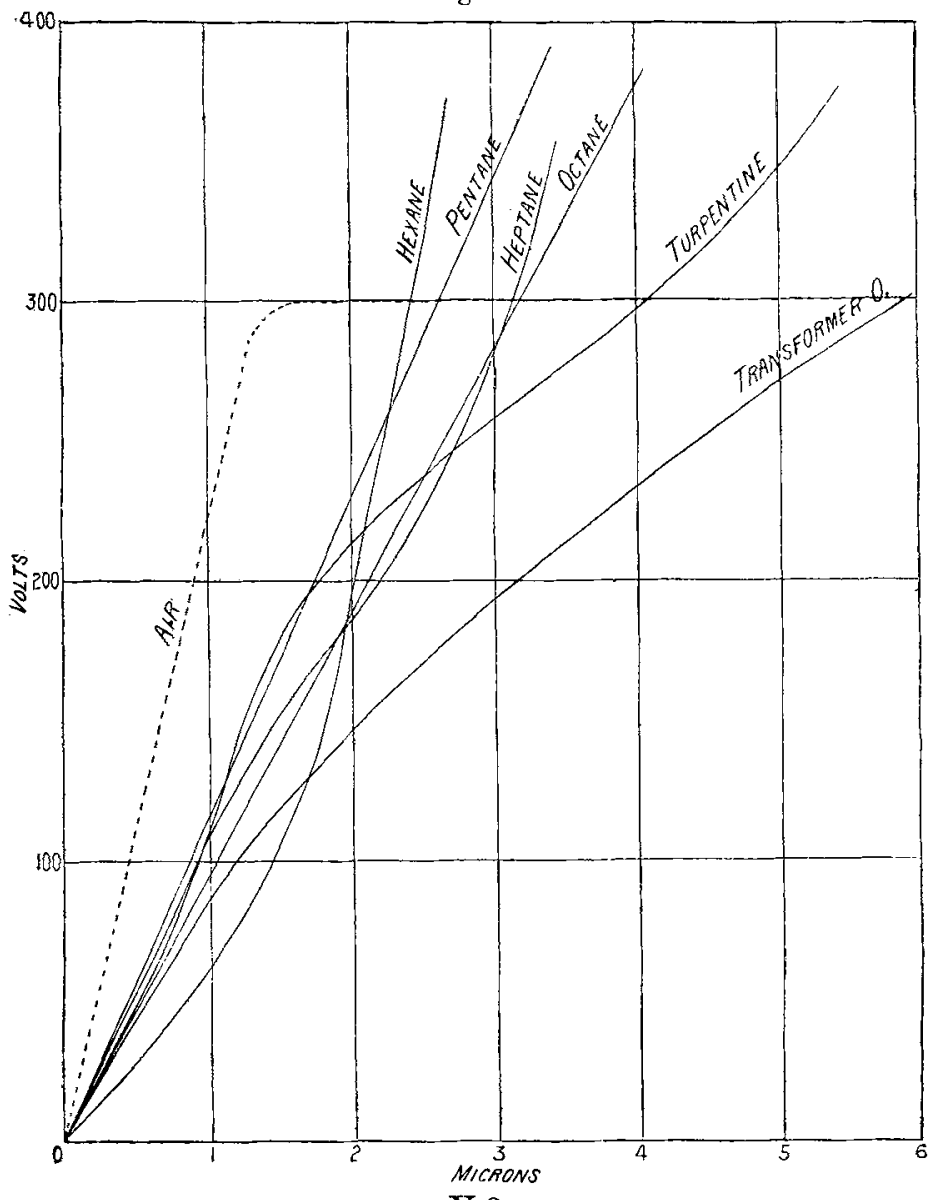

Y 2 
324 Dr. P. E. Shaw on the Disruptive Voltage of Thin

Fig. $t$.

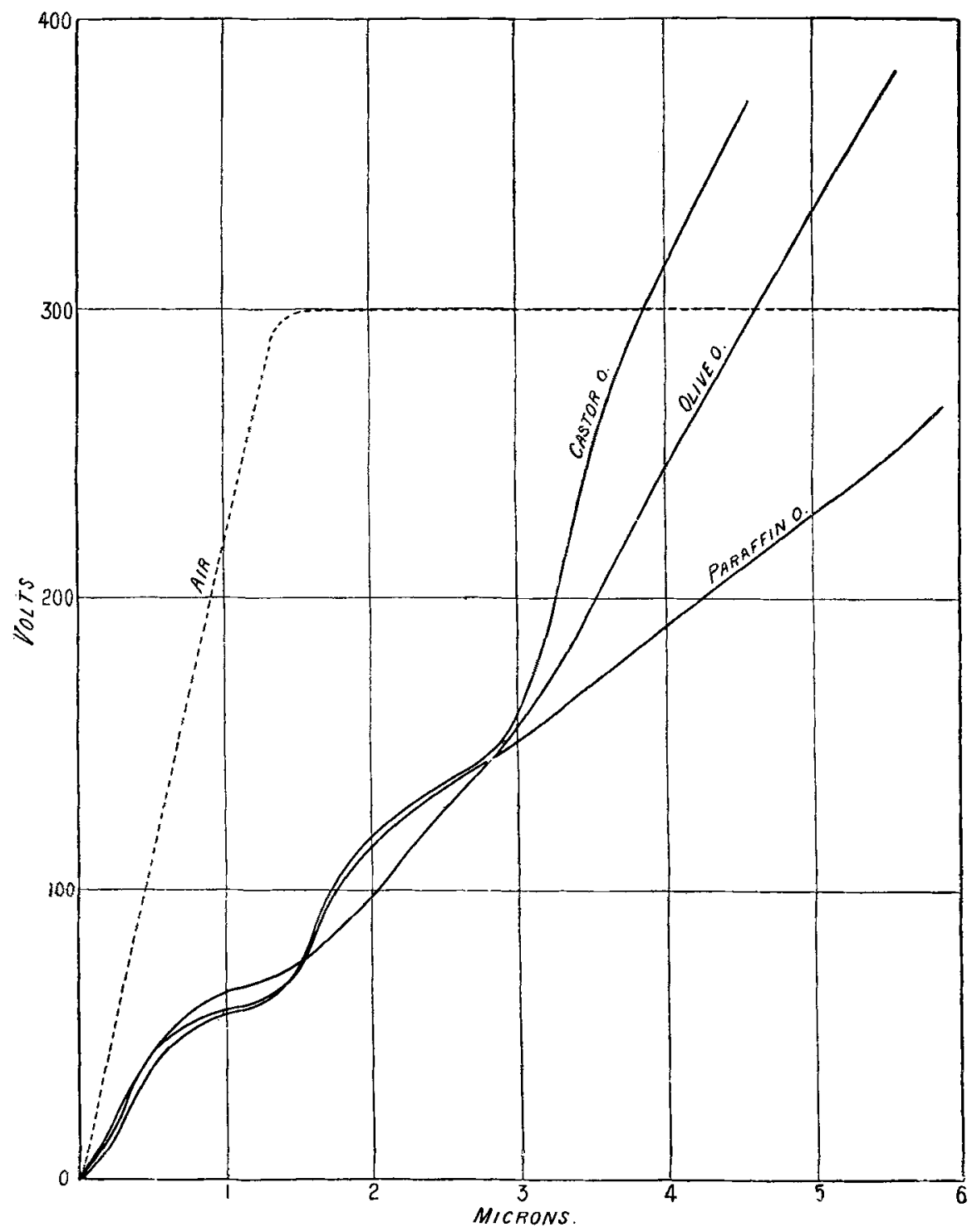


Iiquid Films letueen Tridio-platinum Flectrodes. $\quad 325$

Fig. 5.

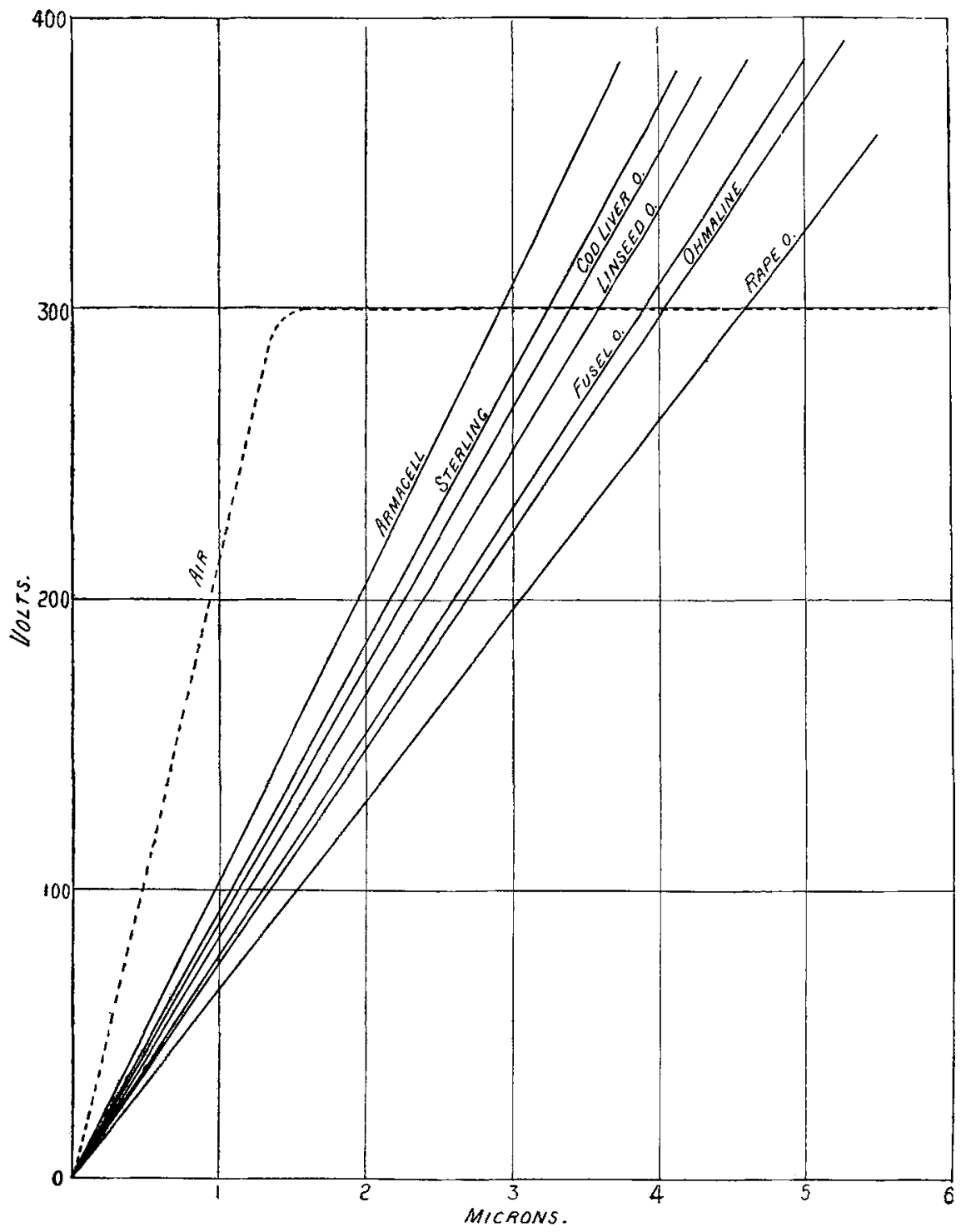


326 Dr. P. E. Shaw on the Disuptive Voltage of Thin

The "knee" occurs at 300 volts, the horizontal part extending to $8 \mu$, i. e. well to the right of the plotting shown. After $8 \mu$ the gradient is very small. Air has greater strength than any liquid for small distances; but the liquid curve in all cases crosses the air curve for discharge lengths varying between $2 \frac{1}{2} \mu$ and $6 \mu$. That is, for any greater distances the liquids have much greater strength than air.

The order of strength for the higher voltages used is roughly:-

Hexane, heptane, armacell, pentane, octane, Sterling varnish, cod-liver oil, linseed oil, fusel oil, ohmaline, castor oil, turpentine, olive oil, rape oil. Paraffin and transformer oil are both weak. Resin oil gave very irregular results, not showing, as might be expected, great strength.

\section{Notes and Precautions.}

1. The roltmeter was carefully standardized.

2. The loud-speaking telephone in the discharge circuit was shunted with non-inductive resistance of a few ohms. Some experimenters in previous researches have kept the discharge surfaces shunted with a voltmeter, so that the discharge is shown by the fall of the voltmeter-pointer. This seems faulty; for when discharge commences, it will be at once violently retarded by an inductive rush from the voltmeter. In the present work the shunted telephone of low resistance indicates discharge, the voltmeter being then cut out and no inductive resistance left in circuit.

3. The members of the homologous series are very volatile; the method employed is to cause drops of them to fall slowly on the discharge surfaces, a fresh drop arriving before the last has evaporated.

4. The discharge is of the nature of a volcanic eruption, the cathode loses material and a distinct pit or crater forms there, while fine dust is scattered on both electrodes. The surfaces approach, but do not always meet on discharge. To avoid dust the surfaces are wiped after each discharge.

5. The discharge surfaces should be treated with care whilst the zero is being obtained. "Make" and "break" should be made as little as possible, and the zero should not be much overrun. The highly polished surfaces, even of the very hard iridio-platinum, are easily damaged for discharge work.

6. If a contact is "wheezy," it is rejected at once; this indicates bad polish, and always produces electrolysis or premature discharge. 
7. The contact sound is invariably clearer and sharper for liquids than for air, and discharge is more definite. Air discharge often occurs partially, i. e. there is a rush of material from the cathode and the contacts approach one another but do not touch. Discharge does not continue; in fact; thi partial discharge seems to retain the tension and for a time stop the complete and final breakdown.

\section{Theory.}

Very short spark-lengths in gases have now been studied by Earhart, Shaw, Kinsley, and Hobbs. The accumulated results of these and the present experiments on short sparklengths in liquids should lead inductively to a theory of the conditions of matter at and between the discharge surfaces. Recently T. Schwedoff (Ann. d. Physik, pp. 918-934, April 1906) has propounded a ballistic theory of the spark-discharge. The fundamental principle he uses is that the discharge between the surfaces is due to the shattering of the molecules of the gas into free ions.; this occurs when the electric strength between the electrodes jointly with the kinetic energy of the ions already existing free, reaches sufficient magnitude. He uses the ballistic law of resistance, in which the frictional force opposing the passage of an ion depends on its speed and on the density of the gas. An expression is finallv derived

$$
v=\frac{300 h_{0} \cdot 10^{-4} \cdot l}{1+\frac{c}{\lambda}\left(1-e^{\frac{b \delta}{c}}\right)},
$$

where $v=$ potential difference on the surfaces;

$l=$ spark-length ;

$\delta=$ density of the gas ;

$h_{0}, c, \lambda$ are constints.

The values of these constants are derived from consideration of the experimental results of Earhart and Shaw. Putting in the constant: and the density of the gas, the P.D. required for any given spark-length is derived.

Schwedoff thus obtains a curve which fairly closely follows that of Earhart, having a knee in the curve at voltage about 350 .

At first sight the similarity between Earbart's experimental curve and Schwedoff's theoretical curve appears to be a striking confirmation of the theory; but careful comparison shows that the two curves are far from coincident near the 
"knee," one set at this important point being only 50 per cent. of the other set. Again, since Earhart's values are used to give the constants in the formula, there is naturally a certain degree of coincidence. But this is not all : the most recent results by Hobbs (loc. cit.) are opposed to Schwedoff's theory in each of the following particulars :-

(1) The critical potential gradients for different gases are identical below the knee.

(2) The critical potential gradients vary very greatly according to the metal used in the electrodes.

(3) Although Earhart did not take note of the fact, his results indicate a short horizontal portion to the curve, the potential gradient there being nil. Hobbs has thoroughly established the horizontal portion for every gas and for every kind of electrode.

As Hobbs points out, his results in conjunction with the previous work of Peace (Proc. Roy. Soc. p. 99, 1892), Strutt (Phil. Trans. p. 377, 1900), Carr (Proc. Roy. Soc. p. 374, 1903), which showed in every case minimum spark-potential in a gas (unless the voliage is very small), seem to indicate that at atmospheric pressure the carriers of the discharge are the ions of the gas for distances greater than $6 \mu$; while they are the ions of the metals of the electrodes for distances less than $2 \frac{1}{2} \mu$; lor distances between $2 \frac{1}{2} \mu$ and $6 \mu$ the P.D. for discharge remains constant, and discharge occurs not at the extreme points of the opposing surfaces, but between points at the distance corresponding to the minimum sparkingpotential, $i$. e. about 350 volts in air.

J. J. Thomson had previously suggested ('Conduction of Electricity through Gases,' p. 386, Camb. Univ. Press) that the metal corpuscles might play a part in these effects. A corpuscle about to leave the electrode feels an electrostatic attraction towards the electrode; if the electric intensity between the electrodes exceeds this, the corpuscle escapes. This critical field works out, from the principle of electric images, to be $8 \times 10^{3}$, which is the order of field in Earhart's experiments. Thus Thomson accounts for the fact that the first part of the curve is straight. This theory, however, may need some modification or amplification in view of the fact, mentioned above, discovered by Hobbs that each metal has its own gradient. Hobbs' curves indicate that great gradient goes with great atomic weight, $i . e$. the heavy metals lose their corpuscles with greatest reluctance. 


\section{Results.}

(1) The insulating liquids do not differ very much from one another in power of resisting discharge, the strength lying between the limits 110 volts per micron and 70 volts per micron, though some liquids seem to have slightly less strength. The range of voltage here spoken of is between 25 and 400 .

(2) Some liquids have a peculiar variation in potential gradient for distances between $1 \mu$ and $2 \mu$. Castor oil, olive oil, and paraffin are cases in point.

(3) All insulating liquids have greater strength than air for P.D. greater than 300 volts ; for less P.D. liquids have much less strength than air.

(4) The results for a homologous series of hydrocarbons do not indicare any simple connexion between composition and power of resisting discharge; the differences found are as likely to be due to accidental impurities as to specific qualities of the liquids.

But these simple substances have specially great dielectric strength. It may be that simplicity of composition makes for strength.

(5) Whereas in the case of gases there is always a horizontal portion in the curve, in liquids there is no such distinct break in the curve between 25 and 400 volts, unless the region at about 60 volts in castor oil, olive oil, and paraffin is of this nature.

(6) No simple connexion can be observed between power of resisting discharge and specific inductive capacity, in liquids.

(7) The temperature throughout was from $15^{\circ} \mathrm{C}$. to $18^{\circ} \mathrm{C}$.

XXXIX. The Fluorescence, Magnetic Rotation, and Temperature Emission Spectra of Iodine Vapour. By R. W. Woon, Professor of Experimental Physics, Johns Hopkins University*.

\section{[Plate IV.]}

$7 \mathrm{TE}$ fluorescence of iodine vapour has been observed by Wiedemann and Schmidt, and also by Konen, but the luminosity appeared to be too feeble to allow a study, either visual or photographic, to be marle of its spectrum. By studying the conditions under which the fluorescence manifests itself to the best advantage, it has been found possible to photograph its spectrum with a large three-prism spectrograph, with its slit narrowed to such a degree that the

\footnotetext{
* Communicated by the Anthor.
} 